\title{
Neural networks, real patterns, and the mathematics of constrained optimization: an interview with Don Ross
}

DON Ross (Winnipeg, 1962) is professor of economics at the University of Cape Town (South Africa) and is program director of methodology at the Center for Economic Analysis of Risk (CEAR) at the J. Mack Robinson School of Business at Georgia State University (USA). He is co-founder of the Research Unit in Behavioral Economics and Neuroeconomics (RUBEN) at the University of Cape Town. From 2012 to 2014 Ross was chair of the executive board of the International Network for Economic Method (INEM), and remains an active member of the editorial boards of the Journal of Economic Methodology, Biological Theory, and Bioeconomics. He holds a PhD in philosophy of science (1990) from the University of Western Ontario.

The scope of Ross' work is staggering. His areas of specialization span economic methodology, game theory, experimental economics of risk and time preferences, addiction and impulsive consumption, the history of economics, and philosophy of science (from logical positivism to scientific metaphysics). Moreover, he has published, refereed, and organized symposia on topics as diverse as biological evolution, human language and signalling dynamics, artificial intelligence (AI) and artificial life modelling, connectionist theories of cognition, cognitive learning theory, analysis of econometric methods, political economy of international trade, African industry studies, and economic development (with emphasis on development in South Africa).

Ross' published monographs include: Philosophy of economics (2014), Economic theory and cognitive science: microexplanation (2005), What people want: the concept of utility from Bentham to game theory (1999), and Metaphor, meaning and cognition (1993). His collaborations include Scientific metaphysics (2012, with James Ladyman and Harold Kincaid), Distributed cognition and the will (2007, with David Spurrett, Harold Kincaid, and G. Lynn Stevens), Handbook of the philosophy of economics (2009, with Harold Kincaid), Midbrain mutiny: the

EJPE'S NoTE: This interview was conducted by James Grayot. He is a PhD candidate at the Erasmus Institute for Philosophy and Economics (EIPE) and copy-editor for the EJPE. He researches issues at the intersection of rational choice theory, cognitive science, and philosophical psychology. 
picoeconomics and neuroeconomics of disordered gambling (2008, with Carla Sharp, Rudy E. Vuchinich, and David Spurrett), Every thing must go: metaphysics naturalized (2007, James Ladyman), and Dennett's philosophy: a comprehensive assessment (2000, with David Thompson and Andrew Brooks). To date, he has published upward of fifty scholarly articles, three dozen book chapters, and a score of reviews and review articles. He has also contributed over a hundred mass-market articles on trade and industrial policy in Africa.

In this interview, professor Ross explores his intellectual roots and surveys his transition from cognitive scientist to economist. He discusses his involvement with Daniel Dennett, the virtues of economic optimization theory, and the merits (and demerits) of integrating economics with its neighbour disciplines.

EJPE: The story of your academic training is very interesting: You started out as a philosopher interested in cognitive science-how did this segue into studying economics? Can you say a little bit about your background as a philosopher and your early interests in cognitive science?

DON ROSS: It was a rapid trip across a wide intellectual landscape. I started off being interested in continental philosophy, specifically Merleau-Ponty's brand of phenomenology. Then I read Doug Hofstadter's Gödel, Escher, Bach (1980), in my final undergraduate year, and was entranced by the deep intellectual roots of the study of machine intelligence. My alma mater, Western Ontario, was strong in cognitive science-Zenon Pylyshyn was there at the time-and it was possible to specialize in cognitive science within the philosophy of science PhD programme. But it was 1986, and the 'new' connectionism was just being born. I was sure that bringing a more biological flavour into AI made sense, so wanted to study that. But the necessary formalism for neural network modelling is the mathematics of optimisation, not formal logic as with classical AI. So although I took courses in foundations of PROLOG and formal semantics, the only place I could get help in learning the math I needed for connectionism was the economics department. I knew many of the economists-and UWO's economics department at the time was one of the best in the world-so I arranged to do some coursework there, and the philosophy department credited it. 
The other critical event in my intellectual development at that time was that I sent one of my course papers to Dan Dennett, and received a detailed reply that was so helpful that I got the paper published in Philosophy of Science (Ross 1990). That marked the beginning of Dan's role as my principal intellectual mentor, which he remains to this day. I owe more to him professionally than to anyone else.

Was economics foreign to you? How did you assimilate? What aspects of economics seemed intuitive (or counter-intuitive) to you given your training as a philosopher of science?

I knew absolutely nothing about economics when I started the courses, unless one counts a bit of Marx. But game theory immediately struck me as wonderful. At that time, in the mid-1980s, game theory was only being rigorously applied in industrial organization (IO) theory. So I attended to IO quite comprehensively before I studied anything else in economics. Gradually I filled in the other branches of micro from there. It was a long time before I started paying any attention to macro, though I now read it as much as anything else. And I ignored development economics completely until I moved to South Africa in 1997 and perceived with my direct senses that it's the most important part of the discipline. If ever one doubts the value of applying effort to economics, look at real poverty.

So did you do all coursework for a PhD in economics while doing your PhD in philosophy? If so, was there a point where you cea sed to think of yourself as philosopher and started thinking "like an economist"?

No, not all the coursework-just the parts that interested me and also taught me the math I needed. As I said, I didn't then take so much as a glance at macroeconomics. It was a few years before I felt sure of myself in applied game theory, and could build IO models and prove theorems. I wish I'd learned more statistics - I had to go back and do that later by myself, and took a full year out of research in the 1990s to just relentlessly do exercises from econometrics textbooks. In 2008 I spent a half-year repeating that regimen at a more advanced level, which was necessary because so much had happened in econometrics in the interim. But from the beginning of my academic career I listed my main research areas as "Connectionist AI, Artificial Life, and Game Theory." Some of my earliest publications were on the foundations of game theory. Also very soon after my $\mathrm{PhD}$, as a philosopher of science, I 
became particularly interested in the social sciences. That led me to read very intensively in the history of economics and in political economy.

As for "thinking like an economist," I found the three primary heuristics for that-'Identify the incentives!,' 'Identify the opportunity costs!,' and 'Look for selection effects!'-as utterly intuitive and sensible from the moment I encountered them. I approached issues in cognitive science through those principles, which made it natural for me to align with Dan Dennett philosophically. I've always felt that on the big issues in both philosophy and economics, my style of thought has been coherent and internally joined-up.

\section{How has Dennett responded to your use of his ideas?}

Dan is very generous in acknowledging the work of others, but he wisely refrains from endorsing other scholars' arguments and conclusions tout court. He's said in print, a few times, that he's learned some things from my work, and naturally that's what one most wants to hear from a mentor. But I'd be worried about him if he ever came out and said "Don is right!" about a big issue. That would be like watching Willie Mays let a ball go between his legs; you don't want to be there. (That really did eventually happen to poor old Willie Mays. But, happily, minds can remain in excellent functional shape right until the end, and Dan's hasn't lost a step.)

I've consistently tried to push Dan to be uncompromising about the 'real' part of his concept of a real pattern (Dennett 1987, 1991). I think he'd acknowledge that I've at least buttressed his retreat from instrumentalism about intentionality with some of my formulations of the shared idea. But Dan is usually more concerned to minister-while applying a lot of gentle but firm correction-to the ontological convictions of non-scientists than I am. This inclines him to promote a role for philosophers in mediating between scientific and folk belief that seems to me to be more appropriately a job for anthropologists.

I may be sounding too much like Paul Churchland here. My view on folk psychology is still closer to Dan's than to his-beliefs and desires are real patterns. They exist only virtually, but being virtual is a way of being real, not a way of being fictional.

"Micro-explanation" is a major theme in your work on economic methodology. For instance, in your (2005) book, Economic theory and 
cognitive science (ET\&CS), you argue that many theories from the cognitive sciences, including neuroscience, can be reconciled with neocla ssical economic theory. Can you say a little about this?

What induces a brain to enact a mind-the very point of mindfulness-is pressure to rationalize its behaviour so as to make itself comprehensible-and, within limits, predictable-to others. In strategic contexts, this also means that it must be predictable to itself. That's all in Dan's work. So when I asked myself how I could extend the Dennettian perspective-which I wanted to do because I truly think it's right-I reasoned, well, I know some economics and I know some neural network modelling, and I know what they have in common mathematically, so let's see if I can anchor Dan's loosely economistic framework into the actual theory as economists understand it.

Do you think that a book like ET\&CS is better suited for philosophers and cognitive scientists, or for economists? Who has the most to gain by reading that book?

Naturally I wish that more economists had read the book. After I actually started doing experimental economics myself, which I took up immediately after finishing the book, I understood why they hadn't. I simply hadn't connected the high-level Samuelsonian theory of the book into the kinds of modelling choices that actually arise in labs. And those are the kinds of economists who are most interested in cognitive science. I think they'll find my (2014) book, Philosophy of economics, much more congenial. I might have thought like an economist, in the sense I described above, from early days; but, although I've done policy work for a long time, I only started doing practical economics that was connected to the topics of my philosophical work about ten years ago. Now, designing and analysing experiments takes up about half of my time. This is largely due to the influence of my other most important intellectual mentor, Glenn Harrison.

It was partly due to this recognition that the second volume in the $E T \& C S$ project wasn't the book about macroeconomics that I'd announced-and am still planning to produce-but, instead, was an application of the ideas of volume 1 to a phenomenon on which I'd been doing experimental work, namely, disordered gambling (Ross et al. 2008).

I do think that economists could learn from the first ET\&CS book how to be more sophisticated in framing their behavioural hypotheses. 
But I'd now advise them to read Philosophy of economics before tackling ET\&CS.

In Philosophy of economics you argue that economics should be distanced from psychology. With this in mind, what are your thoughts on the current state of behavioural economics? How would you respond to behavioural economists who think that psychology is important for understanding how people make decisions?

Let me start with the second question first. I completely agree that we crucially need help from psychology in understanding how people make decisions. I emphasize the distinction between economics and psychology precisely in order to try to promote clarity about how economics and psychology can be complements instead of substitutes for one another. (My complaint about much behavioural economics is that it implicitly replaces economics with the psychology of valuation.)

A typical human behaviour that involves a decision is the result of a vector of causal processes. The economist who is methodologically clear studies external constraints that constitute incentives to narrow choice sets, and the network of expectations about responses of other agents or of whole markets that tend to cause choices to conform (statistically) to the 'general axioms of revealed preference' (GARP) and to implement strategies that are elements of quantal response equilibria (QRE). Psychologists interested in valuation study internal processes that contribute to the framing of choice sets. Often these will be modelled as processes of diffusion and drift in neural or quasi-neural networks. I assume, controversially, that psychological processes are subdeliberative. This reflects my alignment with Dennett's philosophy of mind; once a process is deliberative, it's been framed in public language, and thus involves the person taking the intentional stance toward herself. At that point she's modelling herself strategically and we're in the domain of game theory.

There is a way of integrating these vector elements, provided one has kept them apart in the first place. The method has been developed and illustrated by Glenn Harrison, Lisa Rutström, and their Danish collaborators (Andersen, Harrison \& Rutström 2010). Maximum likelihood estimation of mixture models does not require that all the component models be models of choice, so long as the outputs can be identified with the same event (a 'behaviour'). So mixtures can model both economic and psychological data-generating processes, and 
estimations of mixture models can identify the relative causal weights of economic choices and psychological processes. In some instances, for example bidding in a bond auction, the economic models might account for almost all of the observed behaviour. In other instances-say, ordering either identically priced chocolate or vanilla ice cream-the psychological processes might plausibly turn out to do almost all of the causal work. But to know either of these things in full confidence, we need the economist and the psychologist to work together.

I stress again, however, that to apply this method one must not muddle up the different data-generating processes. In my view the majority of behavioural economics-for example, applications of cumulative prospect theory that fail to distinguish probability loss aversion from utility loss aversion-positively rely on such muddling. Aspects of framing and choice are boiled together in one goulash. If you don't keep in mind that framing and choice are different kinds of processes with different structures, you're going to have too many moving parts in your model, too many degrees of freedom in estimation, and so you're going to have identification problems you can't solve.

\section{How does your current experimental work differ from that of other beha vioural economics?}

I haven't produced experimental innovations. Rather, I've philosophically interpreted and defended as best practice the innovations of my collaborators in the Harrison-Rutström group. Most of their innovations lie not in the individual elements of the methodmaximum likelihood mixture modelling, for example-but in combining effective econometrics with joint estimation of utility function curvature, risk preference structure (for example aversion to static risk versus correlated risk over time), intertemporal discounting, and subjective belief confidence (cf. Andersen, Harrison \& Rutström 2008; Harrison and Rutström 2008). To repeat a much rehearsed line of Glenn's, our group's mantra is to always rigorously align economic theory (which much behavioural economics tosses away), structural econometrics (where much behavioural economics relies on attempted randomization and linear estimation), and sound data elicitation and measurement (unlike those behavioural economists who follow psychologists in trying to motivate subjects using hypothetical rewards).

Making one's best contributions to the collective enterprise of science involves accepting leadership where expertise warrants. In the 
experimental lab and field, Glenn and Lisa are our leaders and I am a soldier.

It's also important in this context to mention our distinguished collaborator George Ainslie. I said earlier that my first deep intellectual interest was in phenomenology. George is the best phenomenologist I know of, probably partly because he was trained by behaviourists. His 'picoeconomics' (1992, 2001) is a very deep, subtle way of understanding the dynamics of selfhood. He's also had a strong influence on my involvement in experiments-he and I collaborated on a couple before either of us became involved with the Harrison-Rutström group. Recently, George, Glenn and I, with a few younger colleagues, have produced some empirical results on human reward bundling about which we're very excited. Watch this space!

What do you think about the relationship between economics and neuroscience? Do you think one discipline has more to gain from the other? Is the discipline of "neuroeconomics" turning into something distinct from either neuroscience or economics?

I've of course had a lot to say about this, very explicitly, in print (Ross 2008, 2011; Harrison and Ross 2010). I was drawn to immerse myself in neuroeconomics from the moment I caught wind of it in 2004, given my combined backgrounds in economic optimization theory and neural network modelling. My considered view today is that the tradition within neuroeconomics that derives directly from the computational neuroscience of learning has produced some outstanding science. I think it's still of only limited relevance to the main concerns of economists, but that's partly because there's still a massive load of bridge-building to be done from the other bank of the river, on the structural econometrics of latent data-generating processes. But then of course there's also quite a lot of neuroeconomics that is devoted to correlating areas of brain activity with economic behaviour as characterized in a naïve way that takes folk psychology much too seriously. I don't predict that the history of science is ultimately going to allocate many pages to work of that kind. And much of that second kind of neuroeconomics involves shockingly bad econometrics, or no econometrics.

You've argued that any well behaved system can be an economic agent (and somewhat controversially, that humans are "atypical" 
economic agents). Instead you claim that things like neurons, bugs, phylogenetic lineages, and even weather patterns are candidates better-suited for the tools of economic analysis. Can you say a little about this?

Not weather patterns, actually, since there's nothing they're trying to optimize. But economic theory is, literally, as a matter of mathematics, a theory of constrained optimization, where the inputs are choices from sets of options and the outputs are measurable in terms of some sort of utility function. Clearly that applies to neurons (or at least groups of neurons), and to insects. It applies to phylogenetic lineages insofar as they're subject to Darwinian selection. That's another point emphasized by Dan Dennett (1995). Those just seem to be plain facts. Of course an economist is always welcome to say "That's not the sort of thing I want to use the theory to model." And it's true, very broadly, to say that biologists (sometimes) use economics to study non-human organisms and ecologies, and neuroscientists (sometimes) use economics to study value computation in the brain, and economists use economics to study human markets. But then my point is that this is a sociological fact, not a methodological one. Methodologically, economic theory applies very usefully to a wide range of phenomena, though where prediction and explanation are concerned it applies only with high levels of uncontrollable error to individual human choices. Fortunately it applies very nicely to markets involving groups of people, if they're constrained by enforced institutional rules that distinguish legitimate from illegitimate ways of transferring property rights.

Following up on that question, some philosophers worry that economics is "imperialistic" in the sense that it invades other disciplines. Do you think this is a legitimate worry?

I think that invocations of imperialism always amount to ad hominem rhetoric. There is no basis on which classes of phenomena should be pre-assigned to disciplines as their property. In saying this I'm not endorsing ambitions by economists to explain the whole social world in their own framework. As I said earlier, very few human behaviours are merely economic. Everyday pricing and resource allocations decisions by normal firms are to a first approximation just economic, though not when the firms in question are selling status goods or services, or when a specific person's idiosyncratic goals influence the decisions. Almost nothing that an individual person does is only economic. So if 
economists try to shed light on whichever phenomena they think they can, this creates no risk that nearby disciplines will be crowded out of influence, at least insofar as the governing goals are scientific rather than political. Of course that final caveat is important. Should people be on guard against attempts by economists to appropriate unwarranted power? Of course-but merely as a special case of the generalization that we all should resist unilateral power grabs by anybody. And, some fantasies on the populist left notwithstanding, economists aren't relatively very powerful, because politicians don't pay much attention to them.

There are various specific points to be added in this area. I think that sociologists would greatly expand their capacity to enlighten the world if more of them learned econometrics. (Increasingly many are, but their institutional structures frequently interfere.) I think that economists should borrow a leaf from philosophers and ground their current debates in deep knowledge of historical debates within their discipline. I think that philosophers would do well to recognize that anthropologists are better equipped to systematically study folk conceptual intuitions than they are. All of this is to say that current disciplinary boundaries, like current national boundaries, are imperfect products of history. That's a good reason to be reverent about neither kind of boundary.

Another important theme in your work is the evolution of human linguistic abilities and other means for public signalling. Most often this is connected to coordination and game theoretic modelling. However, you also make frequent references to philosophers of language, primarily Wittgenstein and Ryle. Would you say that there is an inherent connection between language use (as Wittgenstein and Ryle conceived of it) and game theory? If so, is this a connection that economists practicing game theory should be knowledgeable of? That's an interesting and perceptive question. Language very probably evolved as a strategic instrument-as Ruth Millikan $(1984,1989)$ would put it: facilitating equilibrium selection in games is its proper function. But that's far from its only contemporary function-it's not the main thing that Shakespeare and Bob Dylan, or for that matter Martin Luther King, get up to with it, and theirs are the uses that rightly impress us the most. Economists who have thought rigorously about language have typically spotted the point of modelling it with game theory 
immediately. But I'd encourage them to avoid thus thinking of language reductively, as if sending strategic signals is the only point of it. When Wittgenstein talked about 'language games' he was drawing attention to the fact that people know how to work with language naturally and fluently even though there aren't, and couldn't be, any programmable rules for doing so. That's a very different perspective, indeed almost opposite to the one we take up when we model language as an equilibrium-selection or coordinating technology. I don't want to see economists going around saying "This great philosopher, Wittgenstein, said that language use is a game, so here are some suggested axioms for that game." Most know not to cite David Lewis, who imposes demands on game theory that have no counterpart at all in the mathematics. Economists won't go too far wrong in borrowing from philosophywhen they think about language-if they read Brian Skyrms's work (2010); and they do.

Even if natural language isn't "programmable" in any realistic sense, do you think that philosophers of language can benefit from learning game theory? Do you think there are open philosophical questions about language, or the evolution of language, that game theory can help with?

Absolutely! As I said earlier, the proper function of language is strategic, so in fact if a philosopher wants to fully understand that she had better learn some game theory, because that's what you need to rigorously model strategy. I particularly recommend the deep and pioneering work of Prashant Parikh $(1991,2010)$ in using game theory to understand the tensions between semantics and pragmatics. My own first book was on metaphor. When someone coins an original metaphor, they're trying to bring about a social change, to get other people to see some $\mathrm{X}$ as a $\mathrm{Y}$ where semantic convention hasn't supported the association in question. Whenever anyone tries to influence the behaviour of anyone else, they're entering the territory of strategy and inviting the scrutiny of the game theorist.

What advice would you give to young philosophers interested in economics? What can philosophers contribute to the discipline? Similarly, what advice would you give to young economists? What can economists do from within to improve the discipline? 
To young philosophers who want to apply their skills to economics, my advice would be: find a way to actually get involved in doing some economics. That isn't as difficult to arrange as one might think. The key is to learn some econometrics, and to do so in part by learning to write Stata code. If you can do that, some team of economists will find you useful even on those occasions where you want to make philosophical points with which they're impatient. And chances are that sooner or later, probably sooner, you'll have a theoretical or methodological insight that didn't occur to your economist collaborators, and, bingo, you'll be part of an interdisciplinary team. This will make your critical scrutiny of other economists much more focused, relevant, and persuasive.

As for young economists, I don't need to be hypothetical, because at any given time I'm supervising the doctoral studies of half a dozen of them. They hear my methodological strictures a lot whether they like it or not! These include: (1) When you take up a new study area, learn its deep history from primary sources and trace it back to points in time before the tradition was mathematicised. You're most likely to grasp the subtleties of a domain if you have a good idea of how the late masters would be conceptualized it. I'm talking here about Smith, Ricardo, Marshall, Keynes, and so on-not just Samuelson or Arrow, and certainly not just the papers that have appeared in the American Economic Review. (2) Don't approach your problem by asking which precanned Stata routine will come closest to estimating your model. Ask rather what kind of model structure will fully represent the economics of the issues; then hope that there's a pre-canned Stata routine but be prepared to write new code of there isn't. That way, you cultivate intellectual depth as an economist, not just expertise in the layout of the tool-box.

I don't think that young economists should necessarily set out to 'improve' the discipline in any large-scale, programmatic sense. The discipline isn't in peril because its practitioners impose some benighted ideology on new recruits; it's in peril because learning software manuals is crowding out learning disciplinary history, where all the deepest ideas are to be found. Young economists can also implement wisdom by reading rigorous work from outside the discipline, particularly work of psychologists, sociologists, anthropologists-and, yes, philosophers. 


\section{REFERENCES}

Ainslie, George. 1992. Picoeconomics: the strategic interaction of successive motivational states within the person. Cambridge: Cambridge University Press.

Ainslie, George. 2001. Breakdown of will. Cambridge: Cambridge University Press.

Andersen, Steffen, Glenn W. Harrison, Morten I. Lau, and E. Elisabet Rutström. 2008. Eliciting risk and time preferences. Econometrica, 76 (3): 583-618.

Andersen, Steffen, Glenn W. Harrison, Morten Lau, \& E. Elisabet Rutström. 2010. Behavioural econometrics for psychologists. Journal of Economic Psychology 31: 553-576.

Dennett, Daniel C. 1987. The intentional stance. Cambridge (MA): MIT Press.

Dennett, Daniel C. 1991. Real patterns. The Journal of Philosophy, 88 (1): 27-51.

Dennett, Daniel C. 1995. Darwin's dangerous idea: evolution and the meanings of life. New York: Simon and Schuster.

Harrison, Glenn W. 2008. Maximum likelihood estimation of utility functions using Stata. Working Paper 06-12. University of Central Florida.

Harrison, Glenn W., and Don Ross. 2010. The methodologies of neuroeconomics. Journal of Economic Methodology, 17 (2): 185-196.

Harrison, Glenn W., and E. Elisabet Rutström. 2008. Risk aversion in the laboratory. In Research in experimental economics, vol. 12, Risk aversion in experiments, James C. Cox and Glenn W. Harrison (eds.). Bingley: JAI Press, 41-196

Hofstadter, Douglas R. 1979. Gödel, Escher, Bach: an eternal golden braid. New York: Basic Books.

Kincaid, Harold, and Don Ross (eds.). 2009. Handbook of the philosophy of economics. Oxford: Oxford University Press.

Ladyman, James, and Don Ross. 2007. Every thing must go: metaphysics naturalized. Oxford: Oxford University Press.

Millikan, Ruth Garrett. 1984. Language, thought, and other biological categories: new foundations for realism. Cambridge (MA): MIT press.

Millikan, Ruth Garrett. 1989. Biosemantics. The Journal of Philosophy, 86 (6): 281-297.

Parikh, Prashant. 1991. Communication and strategic inference. Linguistics and Philosophy, 14 (5): 473-513.

Parikh, Prashant. 2010. Language and equilibrium. Cambridge (MA): MIT Press.

Ross, Don. 1990. Against positing central systems in the mind. Philosophy of Science, 57 (2): 297-312.

Ross, Don. 1993. Metaphor, meaning and cognition. New York: Peter Lang.

Ross, Don. 1999. What people want: the concept of utility from Bentham to game theory. Cape Town: University of Cape Town Press.

Ross, Don. Economic theory and cognitive science: microexplanation. Cambridge (MA): MIT Press.

Ross, Don. 2008. Two styles of neuroeconomics. Economics and Philosophy, 24 (3): 473483.

Ross, Don. 2011. Estranged parents and a schizophrenic child: choice in economics, psychology and neuroeconomics. Journal of Economic Methodology, 18 (3): 217-231.

Ross, Don. 2014. Philosophy of economics. Basingstoke: Palgrave Macmillan.

Ross, Don, Andrew Brook, and David Thompson (eds.). 2000. Dennett's philosophy: a comprehensive assessment. Cambridge (MA): MIT Press. 
Ross, Don, James Ladyman, and Harold Kincaid (eds.). 2013. Scientific metaphysics. Oxford: Oxford University Press.

Ross, Don, Carla Sharp, Rudy Vuchinich, and David Spurrett. 2008. Midbrain mutiny: the picoeconomics and neuroeconomics of disordered gambling. Economic theory and cognitive science. Cambridge (MA): MIT Press.

Ross, Don, David Spurrett, Harold Kincaid, and G. Lynn Stephens (eds.). 2007. Distributed cognition and the will. Cambridge (MA): MIT Press.

Skyrms, Brian. 2010. Signals: evolution, learning, and information. Oxford: Oxford University Press. 